\title{
Mapeando elementos do perfil epistemológico de densidade
}

\author{
Mapping elements of the density epistemological profile
}

\author{
Viviane Florentino de Melo ${ }^{1}$
}

Amanda Amantes $^{2}$

\section{Resumo}

Neste artigo apresentamos o mapeamento de elementos do perfil epistemológico de densidade de estudantes do ensino médio e superior. Aplicamos testes a uma amostra de 324 estudantes desses dois níveis com o intuito de identificar a presença de elementos do perfil a partir da segmentação do conceito nas três primeiras zonas: realismo ingênuo, empirismo e racionalismo tradicional. Os testes foram construídos tendo como parâmetro o conteúdo de nível médio. Nossos resultados evidenciam que a consolidação dos conhecimentos referentes ao conceito de densidade que permite a diferenciação de contextos de uso: científico e cotidiano, assim como a apropriação de elementos teóricos para lidar com o conceito, só são constatadas, de modo significativo, em estudantes de nível superior. A partir desses resultados questionamos a formação em nível médio em termos de promoção do desenvolvimento de concepções, uma vez que há evidências de não superação do senso comum. Além disso, parece não haver a instrução necessária para prover elementos teóricos necessários à compreensão de situações empíricas. Por fim, apontamos a necessidade de mais pesquisas, a fim de evidenciar como o processo de escolarização fornece subsídios para que alunos superem o senso comum e consigam operar com teorias científicas.

Palavras-chave: conceito científico de densidade; perfil epistemológico; mapeamento.

\section{Abstract}

This paper presents the mapping of elements of the high school and university students' density epistemological profile. We have applied tests to a sample of 324 students from these two levels to identify profile elements from the segmentation of the concept in the first three zones: naive realism, empiricism, and traditional rationalism. The tests were built using high school-level content as the parameter. Our results show that knowledge consolidation related to the concept of density, which allows the differentiation of contexts of use: scientific and every day, and the appropriation of theoretical elements to deal with the concept, is only found, significantly, in students of higher level. Based on these results, we question the training at the high school level regarding what has been promoted while developing concepts since there is evidence of not succeeding common sense. Also, there seems to be no good teaching to provide the necessary theoretical elements to understand empirical situations. Finally, we point out the need for more research to show how the schooling process provides subsidies for students to overcome common sense and operate with scientific theories.

Keywords: the scientific concept of density; epistemological profile; mapping.

\footnotetext{
${ }^{1}$ Universidade Federal da Bahia | vivianefm@ufba.br

${ }^{2}$ Universidade Federal da Bahia | amanda.amantes@ufba.br
} 


\section{Introdução}

O conceito de densidade é utilizado para a compreensão de vários fenômenos no âmbito das ciências da natureza. $\bigcirc$ fato de a densidade ser tomada como um parâmetro para caracterizar substâncias, possibilita que ela seja utilizada em diversos campos científicos. Por exemplo, no que se refere ao escopo da Biologia, a densidade pode aparecer para apontar diferenças entre os tipos de colesterol. O colesterol considerado bom $(\mathrm{HDL})$, apresenta densidade igual à $1,13 \mathrm{~g} / \mathrm{cm}^{3}$ o que facilita o fluxo sanguíneo; já o colesterol ruim (LDL) possui densidade de $1,04 \mathrm{~g} / \mathrm{cm}^{3}$ e dificulta a passagem sanguínea (MERÇON, 2010).

Na Física, o conceito se relaciona à pressão e ao empuxo para explicar a flutuação dos corpos (AGUIAR, 2018) e, nesse sentido, se relaciona diretamente com o princípio de Arquimedes (PEREIRA, 2009), sendo utilizado também para explicar o comportamento dos gases. Nessa disciplina é comum a utilização do termo massa específica para se referir à densidade de substâncias e o termo densidade é visto de uma forma mais geral, podendo se referir tanto a substâncias, como a objetos compostos por mais de uma substância.

No domínio da Química, a densidade é um conceito fundamental, dada sua importância para a caracterização de substâncias e materiais, para o preparo de soluções e mesmo como parâmetro para a compreensão de fenômenos físico-químicos (SOUZA et. al., 2015). O conceito, derivado da relação entre massa e volume, possibilita remeter tanto a esses entes de forma mensurável como a massa de uma substância no estado sólido, através do uso de uma balança, quanto à massa atômica - teoricamente definida. O mesmo se aplica para o caso do volume.

Densidade é um conceito que pode ser constatado pelo uso da fórmula com entes facilmente mensuráveis, mas que é explicado em última instância por teorias que versam sobre a disposição das partículas no espaço. Nesse sentido, pode ser utilizado didaticamente em uma relação teórico-prática para evidenciar aos estudantes como as teorias químicas explicam fenômenos observáveis.

Sendo densidade uma propriedade das substâncias, para compreendê-la alguns conhecimentos químicos são fundamentais, tais como aqueles que envolvem os vários modelos que constituem o mundo atômico-molecular, assim como as propostas para conceber a organização e as interações entre átomos, íons e moléculas (MORTIMER; MACHADO; ROMANELLI, 2000).

Apesar disso, principalmente no ensino médio, esse conceito é tratado de forma superficial, com ênfase apenas na fórmula que permite calcular o valor numérico da densidade (ROSSI, et. al., 2008) Isso, por vezes, traz um tratamento reducionista ao conceito e ocasiona sua aplicação limitada ou equivocada na explicação dos fenômenos. Um exemplo é apontado por Faria (2010), quando discute o uso da densidade para explicar a imiscibilidade de substâncias. Segundo o autor, a maneira como o termo densidade geralmente é apresentado nas implicações cotidianas, pode acarretar dificuldades de entendimento na parte científica do termo, o que contribuiu para torná-lo um obstáculo epistemológico do tipo verbalista que impossibilita a compreensão dos conceitos científicos no sistema água e óleo.

Outra dificuldade documentada na literatura é o fato de que, para a maioria dos alunos, a densidade representa uma relação entre peso e volume e não entre massa e volume (SMITH; CAREY; WISER, 1986). Fassoulopoulos, Kariotoglou e Koumaras. (2003) explicam que essa confusão se deve ao fato de o peso de um corpo poder ser facilmente 
percebido -bastaria levantá-lo- e a massa ser principalmente um conceito formal. Além disso, a distinção entre massa e peso não é alcançada até pelo menos a idade de 14-15 anos (ROWELL; DAWSON, 1977 apud FASSOULOPOULOS; KARIOTOGLOU; KOUMARAS, 2003).

Para além das limitações de abstração, que podem ser associadas aos estágios do desenvolvimento cognitivo, é documentada a associação de densidade com o peso e o tamanho do objeto, por estudantes de vários níveis de ensino, incluindo o superior (HASHWEH, 2015). Também há relatos de associação errônea de densidade com concentração (ROSSI et. al, 2008).

Xu e Clarke (2012) apontam que dentre os conceitos ensinados nas escolas secundárias, um dos mais difíceis é o de densidade. Esses autores enumeram quatro fatores que, em sua perspectiva, são complicadores para a compreensão do conceito; são eles: i) a impossibilidade de se perceber a densidade de uma forma direta; ii) a necessidade de conhecimento de proporção ou razão para possibilitar seu entendimento; iii) as associações errôneas entre densidade e peso e, v) o uso do termo densidade por outros campos de conhecimento.

Diante da importância do conceito de densidade dentro das ciências e, em especial, da Química, e da problemática levantada, consideramos ser necessária uma lente teórica que nos forneça uma base epistemológica e ontológica para analisar o entendimento desse conceito. Nesse sentido, estamos nos valendo da noção de perfil epistemológico proposta por Gaston Bachelard (1979) para investigar como o processo de escolarização fornece subsídios para que os estudantes construam elementos de suas zonas do perfil epistemológico de densidade. A noção de perfil epistemológico permite lidar com a pluralidade existente de modos de entendimento da realidade. Consideramos essa abordagem valiosa, visto que ela segmenta, a partir de uma perspectiva histórico-filosófica, os diferentes modos pelos quais os conceitos podem ser compreendidos e utilizados.

Diante disso, nosso objetivo com este estudo é investigar como se configuram os elementos do perfil epistemológico de densidade de estudantes do ensino médio e superior. Para tanto, utilizamos como instrumentos de coleta de dados testes compostos por itens construídos a partir desse referencial teórico.

\section{Referencial Teórico}

Em nosso trabalho utilizamos como lente teórica o referencial bachelardiano, mais especificamente a noção de perfil epistemológico. Essa noção deriva dos obstáculos epistemológicos, termo cunhado por Bachelard (1996) para se referir aos obstáculos inerentes ao ato de conhecer. $O$ autor explica que a noção de obstáculo epistemológico pode ser estudada no desenvolvimento histórico do pensamento científico, assim como na prática da educação.

A partir de uma abordagem histórico-filosófica, considerando que a superação dos obstáculos leva ao avanço do conhecimento, mas nunca é definitiva, Bachelard (1979) propõe a noção de perfil epistemológico. Para tanto, o autor toma de empréstimo os sistemas filosóficos, com as devidas ressalvas de toda a problemática de se recortar e retirar um conceito de seu contexto, com o objetivo de "esclarecer os problemas da ciência através da reflexão metafísica" (BACHELARD, 1979, p. 3).

A noção se baseia em um pluralismo filosófico que permite a coexistência de diferentes fases da evolução filosófica, que caminham no sentido de um aumento de coerência 
racional. A proposta considera que apenas uma doutrina filosófica não é capaz de descrever todas as faces de um conceito científico, considerando seu processo de desenvolvimento histórico-filosófico; assim, torna-se necessário utilizar várias doutrinas. Nessa perspectiva, a maneira pela qual uma pessoa compreende e, consequentemente, mobiliza um certo conceito em situações distintas de produção, comunicação e interpretação de significados, diz respeito às doutrinas filosóficas. Um mesmo indivíduo pode apresentar estágios de evolução distintos a depender do conceito em questão e, do contexto discursivo responsável por acioná-lo.

De acordo com essa perspectiva, existem cinco doutrinas filosóficas distintas, as quais Bachelard também chama de níveis ou zonas (adotaremos o termo zona), são elas: realismo ingênuo, empirismo, racionalismo clássico ou tradicional, racionalismo completo e racionalismo discursivo ou dialético. Essa ordem parte da história da construção dos conceitos científicos, de modo que qualquer conceito vai se tornando mais racional à medida que se avança nas zonas do perfil; todavia, Bachelard salienta que nem todos os conceitos apresentam essas cinco zonas.

O perfil epistemológico de um determinado conceito refere-se à frequência de uso que se faz dele em determinada zona. Assim, o perfil é uma autodeclaração do sujeito sobre como ele percebe o uso que faz do conceito nas mais diversas situações de seu cotidiano. Todavia, para que a pessoa possa transitar entre as zonas do perfil e dispor de mais de um modo de compreensão do conceito, faz-se necessário que as zonas científicas sejam construídas ao longo de processo de escolarização.

Em trabalho anterior, (DE MELO; AMANTES; VIEIRA, 2020) utilizamos essa perspectiva teórica para segmentar o conteúdo de densidade abordado no ensino médio e constatamos que ele se divide nas duas primeiras zonas escolarizadas do perfil: empirismo e racionalismo tradicional. Entretanto, para fins didáticos, consideramos frutífero analisar também a zona não escolarizada - realismo ingênuo - uma vez que se espera que os estudantes iniciem seus estudos sobre o conceito dispondo dessa zona e que, ao longo do processo de ensino, abandonem seu uso em situações e contextos científicos.

A zona do realismo ingênuo é a que a maioria das pessoas utiliza em seu cotidiano para lidar com os conceitos. Ela se caracteriza por ter um grande apelo à subjetividade. Bachelard (1979) usa o exemplo de massa e explica que no realismo ingênuo, massa é algo grave e volumoso, algo que o sujeito constata pela visão. Essa apreciação visual acarreta a construção de afirmações imediatas, sem uma necessidade de objetivação, o que resulta em "teorias" fragmentadas e locais, não passíveis de generalização.

No que se refere ao conceito científico de densidade, consideramos que nessa zona ele é muitas vezes entendido como sensação de peso. Essa percepção pode ser constatada por expressões utilizadas por estudantes no início do estudo do conceito; tais como - "é muito pesado por seu tamanho" para se dizer que um objeto é denso (FASSOULOPOULOS; KARIOTOGLOU; KOUMARAS, 2003). Paralelamente ao conceito de massa, denso seria algo pesado o suficiente, mais especificamente para sólidos e, no caso de líquidos, denso equivaleria a um líquido viscoso. Nessa zona do perfil caberiam afirmações cotidianas que associam erroneamente densidade a volume ou massa (DE MELO; AMANTES; VIEIRA, 2020).

A zona do empirismo rompe com o realismo ingênuo através da necessidade de objetificação do conceito. O sujeito não pode mais ser o instrumento de medida. A objetivação é conseguida por meio de experiências concretas, com objetos que podem ser medidos, pesados e comparados através de uma técnica instrumental dirigida. No que diz 
respeito ao conceito de massa, Bachelard (1979) explica que nessa zona é possível calcular a massa de forma objetiva, unívoca.

Para o conceito de densidade, nessa zona se enquadram conclusões obtidas através de experiências simples, tais como flutuação de sólidos em líquidos, a disposição de líquidos imiscíveis com densidades distintas e o cálculo do valor numérico através da razão da massa pelo volume (que podem ser facilmente constatados através de uma balança e um recipiente medidor de líquidos) (DE MELO; AMANTES; VIEIRA, 2020).

A doutrina seguinte - racionalismo tradicional, supera e engloba o empirismo ao considerar o conceito a partir das relações que estabelece com outros. Tal consideração impossibilita que o conceito seja definido de uma vez por todas, como na zona anterior. Bachelard explica que essa zona se constituiu com o surgimento da mecânica racional de Newton, no final do século XVII. Assim, a utilização simples e absoluta de uma noção cede espaço para a utilização correlativa das noções. No que se refere à massa, essa "... define-se então num corpo de noções e já não apenas como um elemento primitivo de uma experiência imediata e direta" (BACHELARD, 1979, p. 16).

Quadro 01. Entendimento do conceito nas zonas do perfil

\begin{tabular}{|c|c|c|}
\hline $\begin{array}{c}\text { Realismo } \\
\text { Ingênuo (RI) }\end{array}$ & Empirismo (E) & Racionalismo Tradicional (RT) \\
\hline \multirow[t]{4}{*}{$\begin{array}{l}\text { Associar o } \\
\text { conceito à forma, } \\
\text { tamanho ou peso }\end{array}$} & $\begin{array}{l}\text { Saber operar com a } \\
\text { fórmula de densidade } \\
\qquad \mathrm{d}=\mathrm{m} / \mathrm{v}\end{array}$ & $\begin{array}{c}\text { Saber que a densidade é } \\
\text { dependente da configuração } \\
\text { molecular ou cristalina dos átomos } \\
\text { ou moléculas que compõem a } \\
\text { substância }\end{array}$ \\
\hline & $\begin{array}{l}\text { Saber a relação entre } \\
\text { densidade e flutuação }\end{array}$ & $\begin{array}{c}\text { Saber calcular a densidade } \\
\text { utilizando elementos } \\
\text { abstratos/teóricos }\end{array}$ \\
\hline & $\begin{array}{c}\text { Saber calcular a } \\
\text { densidade de misturas/ } \\
\text { soluções }\end{array}$ & $\begin{array}{c}\text { Saber relacionar o conceito com } \\
\text { forças intermoleculares / polaridade } \\
\text { para substâncias puras. }\end{array}$ \\
\hline & $\begin{array}{l}\text { Identificar a variação no } \\
\text { valor de densidade de } \\
\text { misturas por meio da } \\
\text { adição de solutos e/ou } \\
\text { solventes. }\end{array}$ & $\begin{array}{l}\text { Saber relacionar o conceito com } \\
\text { forças intermoleculares/ polaridade } \\
\text { para misturas. }\end{array}$ \\
\hline
\end{tabular}

Fonte: Adaptado de De Melo, Amantes e Vieira (2020)

A constituição racional da Química, que inaugura a zona do racionalismo tradicional nesse campo, se deu ao longo de todo o século XIX. Teve início com a hipótese atômica de Dalton que foi sendo desenvolvida e transformada pelo estabelecimento de novos conceitos como a noção de molécula, valências e organização espacial das partículas, o que culminou em uma teoria atômico-molecular clássica (MORTIMER, 1992). Assim, no racionalismo tradicional a faceta do conceito de densidade que surge diz respeito as teorias que explicam a estrutura interna de um material, seja ela cristalina, atômica ou molecular, ou seja, os 
fatores que, em última instância, determinam o valor numérico encontrado na zona anterior (DE MELO; AMANTES; VIEIRA, 2020).

No quadro 1, apresentamos a segmentação do conceito nas três primeiras zonas do perfil.

A partir da segmentação dos entendimentos do conceito de densidade em cada uma das zonas do perfil, foram construídos itens para acessar o entendimento dos estudantes. Nossos instrumentos são compostos por itens representativos de cada uma das zonas. Discorremos a seguir acerca dos sujeitos que participaram de nossa pesquisa assim como dos instrumentos de coleta.

\section{Metodologia}

\section{I - Sujeitos e instrumentos de coleta}

A fim de investigar como se configuram os elementos do perfil epistemológico de densidade de estudantes de dois níveis de ensino, aplicamos dois questionários devidamente validados (MELO, 2020) para uma amostra de 324 sujeitos. Os instrumentos foram respondidos por 249 alunos do terceiro ano do ensino médio de uma escola pública de Salvador e 75 alunos de graduação: 25 do curso de licenciatura em Física e 50 de licenciatura em Química, de duas Universidades públicas da Bahia. Desses, responderam ao teste 1, 141 estudantes (113 do ensino médio e 28 do superior); o teste 2 foi respondido por 183 estudantes (136 do ensino médio e 47 do ensino superior).

Nossos instrumentos foram construídos a partir da segmentação do conceito nas três primeiras zonas do perfil. Para a zona do empirismo, foram construídos dois tipos de itens: básicos e complexos. Esses itens se diferem pela articulação lógica entre conceitos e conhecimentos necessários para respondê-los. Assim sendo, itens que podem ser resolvidos com aplicação direta de uma fórmula (sem a necessidade de mudança de unidades, por exemplo) ou com simples relações de flutuação entre líquidos, referem-se aos denominados básicos. Os itens em que se faz necessário realizar transformações de unidades, efetuar cálculos com números decimais, aplicação não direta de fórmulas e/ou estabelecimento de relações entre variáveis, dizem respeito aos complexos.

Essa diferenciação para os itens do empirismo foi realizada para verificar se conhecimentos matemáticos e relações entre outros conceitos teriam influência na construção dessa zona do perfil. Assim, construímos itens mais diretos, com o objetivo de identificar se os estudantes possuem o entendimento e itens nos quais o entendimento também é necessário, mas há um peso maior no raciocínio lógico ou no ferramental matemático.

Ambos os testes foram construídos utilizando questões em camadas. Esse tipo de questão é composto por pares de itens, de modo que cada item é acompanhado de outro no qual o estudante é indagado acerca das razões que o fizeram optar pela alternativa no item anterior. Assim, além de ter acesso ao conhecimento do estudante, pode-se também inferir sobre o raciocínio utilizado para responder o item. Para fins de análise, as questões em camadas foram desmembradas em seus itens, de modo que cada questão originou dois itens, um referente à primeira camada e outro à segunda.

Como foram construídos dois tipos de itens para a zona do empirismo, passaremos a diferenciar as categorias dos itens daqui em diante em termos de natureza. Assim, temos 
itens que marcam a iniciação do perfil que pertencem a zona do realismo ingênuo que são de natureza 1, itens do empirismo básico, de natureza 2, empirismo complexo, natureza 3 e, finalmente itens do racionalismo tradicional, natureza 4. A tabela abaixo relaciona os itens de cada teste com suas respectivas naturezas.

Tabela 1. Relação entre itens e suas naturezas nos testes 1 e 2

\begin{tabular}{cccccccccccc}
\hline T - 1 & Item & 1 & 2 & 3 & 4 & 5 & 6 & 8 & 9 & 10 \\
\cline { 2 - 12 } & Natureza & 2 & 3 & 4 & 1 & 2 & 2 & 3 & 3 & 4 \\
\cline { 2 - 12 } & Item & 11 & 12 & 13 & 14 & 15 & 16 & 17 & 18 & \\
\cline { 2 - 12 } T-2 & Natureza & 3 & 4 & 1 & 2 & 4 & 4 & 3 & 3 & \\
\cline { 2 - 11 } & Item & 1 & 2 & 3 & 4 & 5 & 6 & 7 & 8 & 9 \\
\cline { 2 - 11 } & Natureza & 2 & 4 & 2 & 1 & 3 & 4 & 2 & 4 & 3 \\
\cline { 2 - 11 } & Item & 11 & 12 & 13 & 14 & 15 & 16 & 17 & 18 & 19 \\
\cline { 2 - 11 } & Natureza & 2 & 4 & 4 & 1 & 3 & 4 & 2 & 4 & 3 \\
\hline
\end{tabular}

Fonte: Autoras

A seguir, nas figuras 1, 2, 3 e 4 apresentamos exemplos de questões de cada uma das naturezas categorizadas nos testes. A figura 1 refere-se a itens de marcação de iniciação do perfil, de natureza 1.

Figura 1 - Exemplo de questão composta por itens de natureza 1.

(Questão 4) Considere as três chapas abaixo, cada uma com suas respectivas dimensões, todas formados pelo mesmo material, a mesma temperatura.
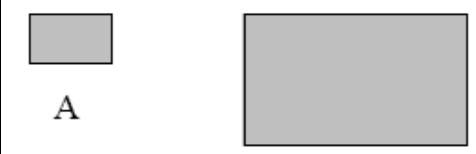

B

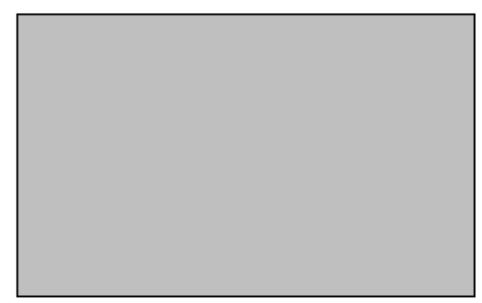

$\mathrm{C}$

\begin{tabular}{|c|c|}
\hline $1^{a}$ Camada & $2^{a}$ Camada \\
\hline Com relação à densidade delas, & Qual das seguintes explicações é o motivo de
\end{tabular}
podemos afirmar que: você ter marcado a resposta para a pergunta anterior?

(A) A densidade da A é a menor.

(B) A densidade da A é a maior. (C) A densidade das três é a mesma.

(D) A densidade da B é a média da densidade da A e da C.

(E) A densidade da $C$ é o dobro da de $B$.
(A) Como B tem volume e massa intermediária em relação a A e $C$, sua densidade é a média dos valores de A e C.

(B) Como as três são formadas pelo mesmo material, a densidade delas é a mesma.

(C) Como A é a menor, ela é a mais leve, logo a menos densa.

(D) Como a C tem aproximadamente o dobro do tamanho da

$B$, sua densidade também segue essa relação.

(E) Como A é a menor, a massa dela é mais concentrada, por isso ela é a mais densa.

\section{Fonte: Teste 1}


Nas figuras 2 e 3, apresentamos questões referentes ao segundo nível da zona do empirismo - Saber a relação entre densidade e flutuação. Para o teste 2, a questão era mais direta, sendo considerada mais básica, de natureza 2 (ver figura 2), para o teste 1, essa questão envolvia mais elementos a serem considerados, o que a torna mais complexa, natureza 3 (ver figura 3), Na construção dos instrumentos procuramos igualar o nível de dificuldade, assim as questões mais e menos complexas foram igualmente distribuídas entre os dois testes, assim como as questões das outras duas zonas do perfil.

Figura 2 - Exemplo de questão composta por itens de natureza 2

(Questão 8) Para identificar três líquidos - de densidades 0,8 g/cm3; 1,0 g/cm3 e 1,2 g/cm3 - um analista dispõe de uma pequena bola de densidade $1,0 \mathrm{~g} / \mathrm{cm} 3$. Conforme as posições das bolas apresentadas no desenho a seguir.

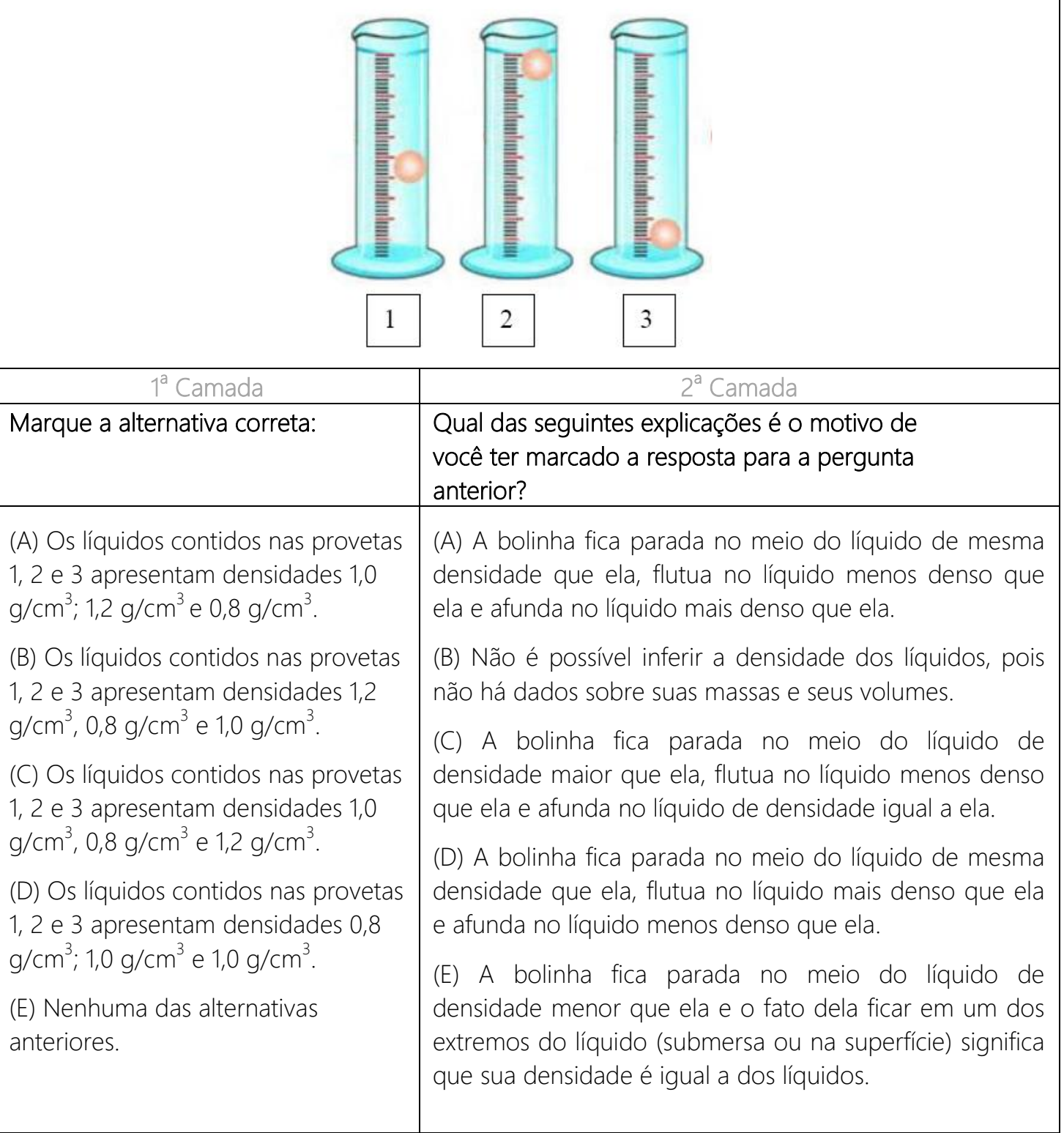

Fonte: Teste 1 
Figura 3 - Exemplo de questão composta por itens de natureza 3

(Questão 7) Três líquidos (água, benzeno e clorofórmio) foram colocados numa proveta, originando o seguinte aspecto:

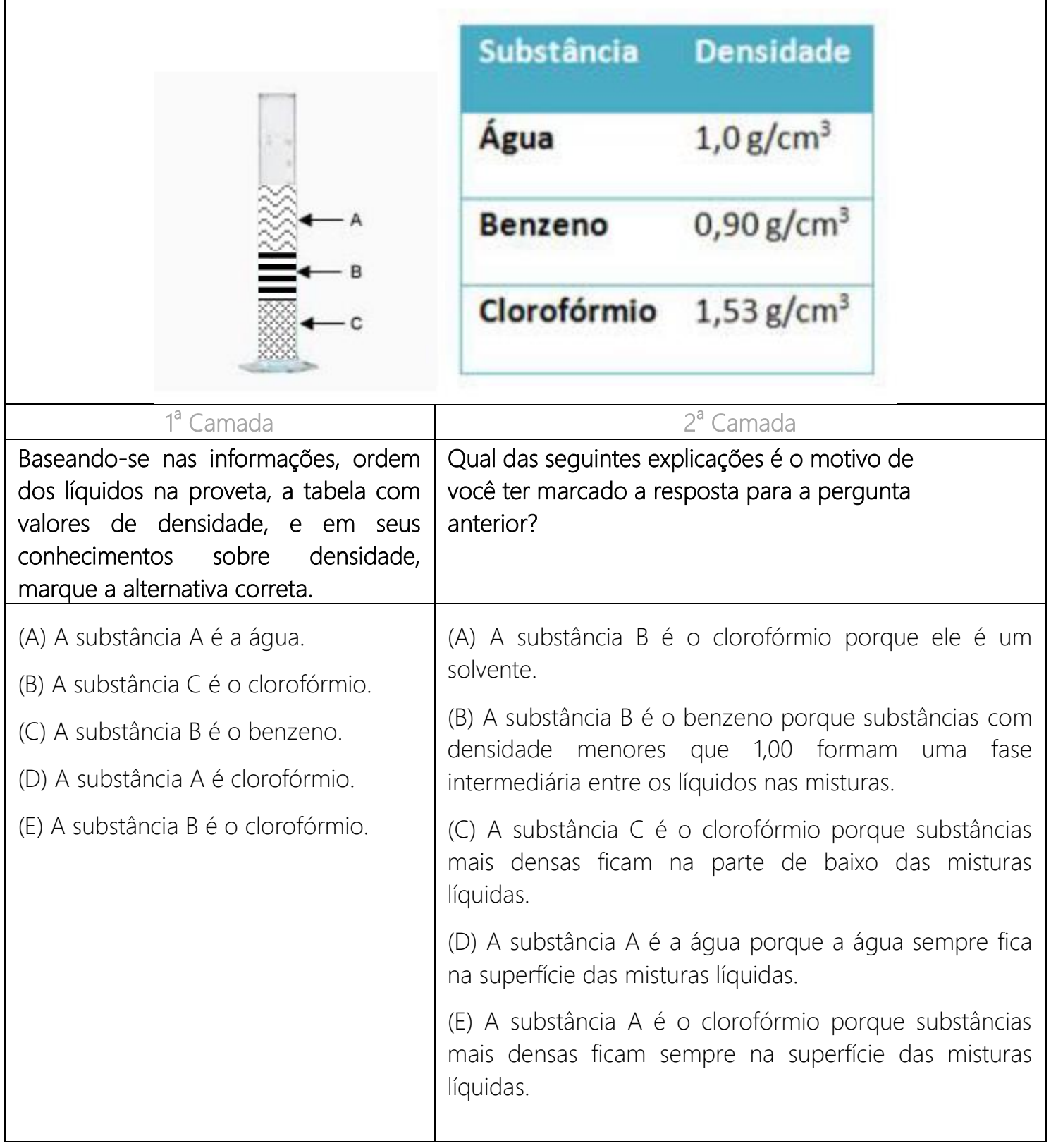

Fonte: Teste 2

A figura 4 refere-se a itens da zona do racionalismo tradicional, natureza 4, primeiro nível de entendimento - Saber que a densidade é dependente da configuração molecular ou cristalina dos átomos ou moléculas que compõem a substância. 
Figura 4 - Exemplo de questão composta por itens de natureza 4

\begin{tabular}{|c|c|}
\hline $1^{\mathrm{a}}$ Camada & $2^{a}$ Camada \\
\hline Marque a alternativa correta: & $\begin{array}{l}\text { ual das seguintes explicações é o motivo de } \\
\text { cê ter marcado a resposta para a pergunta } \\
\text { terior? }\end{array}$ \\
\hline $\begin{array}{l}\text { (A) Os icebergs flutuam na água do mar } \\
\text { devido à modificação no arranjo entre as } \\
\text { moléculas de água que ocorre quando elas } \\
\text { se congelam. } \\
\text { (B) Os icebergs flutuam porque estão } \\
\text { submetidos à baixas temperaturas. } \\
\text { (C) Os icebergs flutuam porque são } \\
\text { formados por resíduos provenientes da } \\
\text { poluição dos oceanos, o que os mantém no } \\
\text { estado sólido pela ação das forças de } \\
\text { London. } \\
\text { (D) Os icebergs flutuam apenas em água } \\
\text { salgada, pois ela é mais densa devido ao } \\
\text { processo de solvatação dos íons dos sais } \\
\text { pelos dipolos das moléculas de água. } \\
\text { (E) Os icebergs flutuam porque são sólidos } \\
\text { reticulares de moléculas de } \mathrm{H}_{2} O \text { O. }\end{array}$ & $\begin{array}{l}\text { (A) As forças intermoleculares de London, presentes } \\
\text { nos resíduos, são mais fracas que as da água. } \\
\text { (B) Sólidos reticulares são formados por átomos } \\
\text { ligados a seus vizinhos por ligações covalentes em } \\
\text { todo o sólido, de modo que eles não são submetidos } \\
\text { à ação de forças intermoleculares, e por isso, são } \\
\text { pouco densos. } \\
\text { (C) A diminuição da temperatura reduz a energia das } \\
\text { moléculas fazendo com que elas fiquem mais } \\
\text { próxima umas das outras. } \\
\text { (D) Ao passar para o estado sólido as moléculas de } \\
\text { água adquirem uma nova configuração molecular na } \\
\text { qual existe mais espaço entre as moléculas. } \\
\text { (E) Durante o processo de solvatação dos íons, as } \\
\text { moléculas de água têm seus comprimentos de } \\
\text { ligação diminuídos devido à atração que se } \\
\text { estabelece. }\end{array}$ \\
\hline
\end{tabular}

Fonte: Teste 2

\section{II- Procedimento de Análise}

Em estudo prévio, validamos nosso instrumento através de análises no software Winsteps (LINACRE, 2010) (MELO, 2020). Na modelagem os testes 1 e 2 apresentaram os respectivos ajustes: confiabilidade dos itens de 0,89 e 0,94; confiabilidade das pessoas 0,71 e 0,74; variâncias explicadas pelas medidas de 26,6\% e 25,9\%, ficando bem próximos dos valores modelados (26\% para o teste 1 e $25,4 \%$ para o 2), alfa de Cronbach igual a 0,79 e 0,78 (o que indica boa consistência interna).

No que se refere ao ajuste dos itens foi utilizado os índices infit e outfit da estatística MNSQ. Dois itens não apresentaram valores ideais e foram descartados na análise aqui relatada (item 7 do teste 1 e o item 10 do teste 2). Pelas análises concluímos que 0 instrumento acessa duas facetas do conhecimento sobre densidade, uma referente à zona do empirismo e outra do racionalismo.

As análises relatadas neste estudo foram realizadas com os seguintes objetivos:

1) Identificar as zonas do perfil dimensionadas pelos testes e,

2) Investigar como se configuram os elementos do perfil epistemológico de densidade dos estudantes. 
Para identificar as zonas do perfil dimensionadas pelos testes utilizamos como dados os índices de dificuldade dos itens obtidos através da modelagem Rasch. Analisamos se havia diferença estatística entre as dificuldades dos itens a depender de sua natureza (categoria que engloba as zonas do perfil), para tanto utilizamos o software SPSS (IBM_CORP, 2011); uma vez confirmada a diferença, procedemos as análises referentes ao perfil.

Para investigar a configuração dos elementos do perfil, utilizamos como dados a porcentagem da frequência normalizada das respostas obtidas pelos itens a depender de suas naturezas. Utilizamos esse tipo de frequência devido ao número de itens de cada categoria não ser o mesmo. Essas análises foram realizadas no software Excel.

\section{Análise e resultados}

\section{I- Identificação das zonas do perfil}

O objetivo deste estudo foi verificar se os testes correspondiam ao modelo teórico do perfil epistemológico para o conceito de densidade. Os testes foram construídos tendo por base a segmentação do conceito nas três primeiras zonas do perfil; por meio dessas análises iremos constatar se os testes refletem a hierarquia das zonas. De acordo com esse referencial teórico, cada uma das zonas subsequentes engloba e amplia os conhecimentos da anterior. Assim, espera-se que haja diferença de dificuldade nos itens a depender da zona a qual eles correspondem.

Iniciamos nossa análise verificando a possibilidade de considerar os dois testes em conjunto. Como foram aplicados a amostras diferentes, para que fossem analisados em conjunto foi preciso certificar-se de que a dificuldade de um deles não fosse significativamente diferente da dificuldade do outro. Ou seja, foi preciso avaliar se as amostras poderiam ser consideradas como homogêneas, apresentando o mesmo padrão de acertos e erros. Para isso, foi realizado um teste ANOVA entre as dificuldades dos itens do teste 1 e do teste 2 , cujo resultado indicou não haver diferença entre elas ( $F=0,197$, $p=0,660)$.

Prosseguindo com a análise, o objetivo foi identificar se havia hierarquia entre itens de naturezas distintas: realismo ingênuo $(n=1)$, empirismo básico $(n=2)$, empirismo complexo $(n=3)$ racionalismo tradicional $(n=4)$. De acordo com a nossa perspectiva teórica, espera-se que itens do racionalismo tradicional apresentem um nível de dificuldade maior que itens do empirismo e que esses sejam mais difíceis que os do realismo ingênuo.

Para identificar essa hierarquia, utilizamos como dados as médias de dificuldades dos itens estimadas em uma escala intervalar, a partir da modelagem Rasch. As médias de dificuldades dos itens de cada natureza foram plotadas no gráfico 1.

O gráfico 1 apresenta, no eixo $x$, cada uma das categorias de itens que dispomos $(n=1$ Realismo Ingênuo, $\mathrm{n}=2$ Empirismo básico, $\mathrm{n}=3$ Empirismo complexo, $\mathrm{n}=4$ Racionalismo Tradicional). No eixo y, é apresentada a média de dificuldade dos itens de cada categoria, representada pela marcação da barra mediana de erro. Os itens da natureza do 
racionalismo tradicional foram os mais difíceis com média igual a 0,37 logits ${ }^{3}(S D=0,62$ ), seguido dos itens do empirismo complexo com média igual a 0,16 $(S D=0,60)$, itens do realismo ingênuo $-0,28(S D=0,29)$ e por fim, os itens do empirismo básico, com média de dificuldade igual a $-0,56(S D=0,53)$.

Gráfico 1 - Médias das dificuldades dos itens a depender de sua natureza

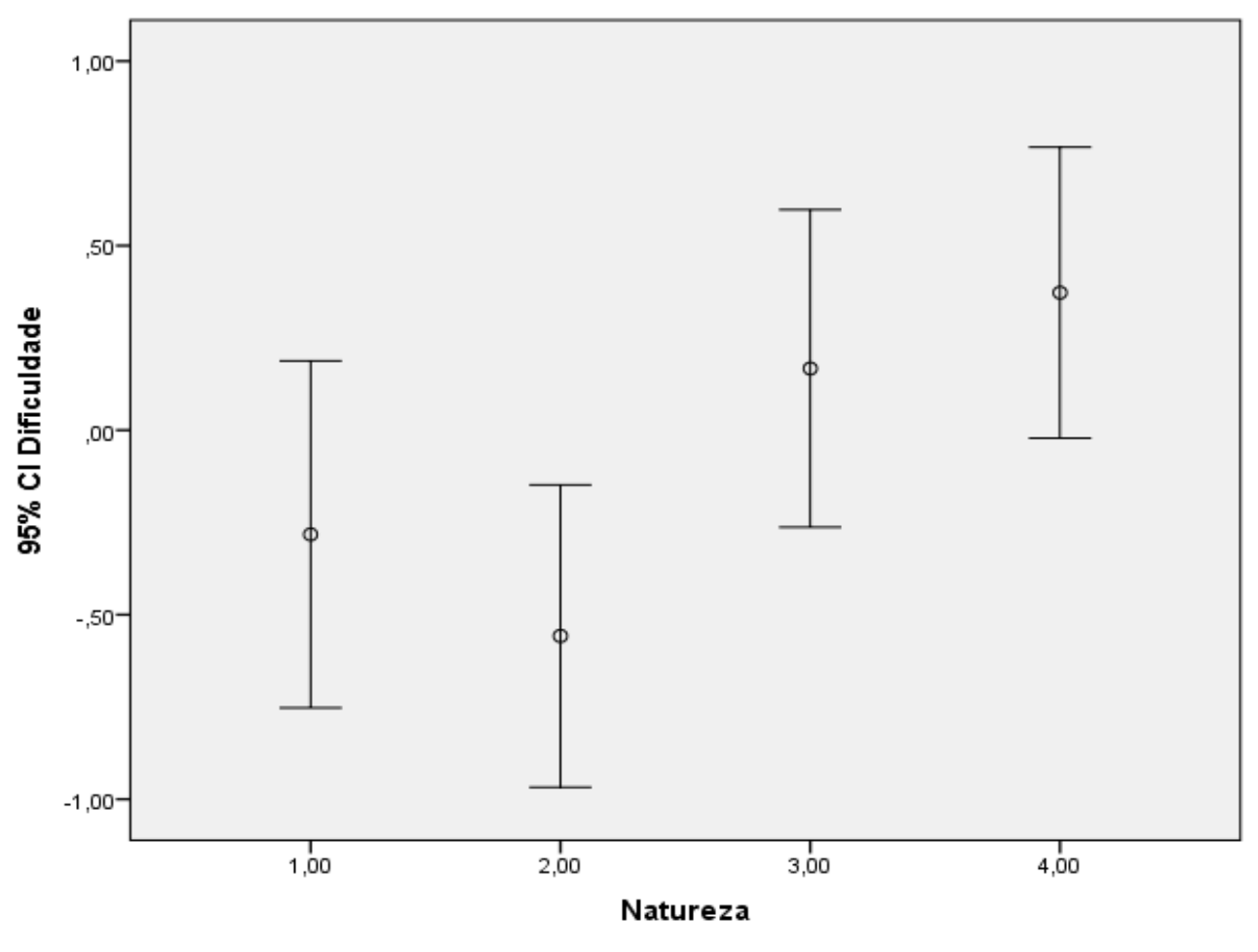

A categoria que apresentou menor dificuldade foi a do empirismo básico. De acordo com nossa perspectiva teórica era esperado que os itens com menor dificuldade fossem os correspondentes a zona do realismo ingênuo. De acordo com a noção de perfil epistemológico, essa zona reflete o uso cotidiano que se faz do conceito. Em nossos testes, o erro em itens dessa natureza indica que o sujeito ainda não se apropriou da visão científica do conceito. Como os estudantes de nossa amostra já haviam estudado o conceito de densidade era esperado que esses itens fossem os mais fáceis dos testes.

Itens do empirismo complexo apresentaram médias de dificuldades distintas de itens referentes ao empirismo básico, apesar dos itens remeterem aos mesmos entendimentos. As médias de dificuldade desses itens ficaram mais próximas a itens de natureza racionalista do que do empirismo básico. Todavia, é necessário verificar se essas médias se diferenciam do ponto de vista estatístico.

Quanto a hierarquia das zonas, podemos perceber uma tendência crescente no nível de dificuldade em direção aos itens do racionalismo tradicional. Esse resultado valida a hierarquia teórica que subsidiou a elaboração dos testes, o que nos permite fazer uma

\footnotetext{
${ }^{3}$ Escala intervalar de medida de proficiência, cujos intervalos são os mesmos ao longo da régua e o objetivo é comparar a dificuldade do item em relação à dificuldade dos sujeitos.
} 
análise do perfil da amostra mais robusta, uma vez que temos uma evidência empírica de que existem diferenças entre as zonas.

Contudo, para nos certificar de que essas diferenças representam realmente uma hierarquia, testamos se essas médias são distintas do ponto de vista estatístico. Assim, nosso próximo passo foi identificar se havia diferença estatística nas dificuldades dos itens a depender de suas naturezas. Através dessa análise, podemos afirmar se itens de uma dada natureza foram estatisticamente mais fáceis ou mais difíceis que outra para nossa amostra.

Pelo teste ANOVA, identificamos que há diferença de dificuldade dos itens a depender de sua natureza $(F=5,221, p=0,005)$. Para efetuar a comparação entre cada uma das categorias realizamos um teste pos-hoc para avaliar o resultado da ANOVA. Como os grupos de natureza distinta apresentaram variância homogênea $(L=0,781, p=0,513)$ essa comparação foi realizada pelo pos-hoc Bonferroni. A tabela 2, apresenta os resultados.

Tabela 2 - Resultado do teste de Bonferroni

\begin{tabular}{|c|c|c|c|c|c|c|c|}
\hline \multicolumn{8}{|c|}{ Dependent Variable } \\
\hline & \multirow[t]{2}{*}{$\begin{array}{c}\text { (I) } \\
\text { Natureza }\end{array}$} & \multirow[t]{2}{*}{$\begin{array}{c}(\mathrm{J}) \\
\text { Natureza }\end{array}$} & \multirow{2}{*}{$\begin{array}{c}\text { Mean } \\
\text { Difference } \\
(\mathrm{I}-\mathrm{J})\end{array}$} & \multirow[t]{2}{*}{$\begin{array}{l}\text { Std. } \\
\text { Error }\end{array}$} & \multirow[t]{2}{*}{ Sig. } & \multicolumn{2}{|c|}{$\begin{array}{l}\text { 95\% Confidence } \\
\text { Interval }\end{array}$} \\
\hline & & & & & & $\begin{array}{l}\text { Lower } \\
\text { Bound }\end{array}$ & $\begin{array}{l}\text { Upper } \\
\text { Bound }\end{array}$ \\
\hline \multirow[t]{12}{*}{ Bonferroni } & \multirow[t]{3}{*}{1} & 2,00 & ,27528 & ,34167 & 1,000 &,- 6877 & 1,2382 \\
\hline & & 3,00 &,- 44950 & ,33637 & 1,000 & $-1,3975$ & ,4985 \\
\hline & & 4,00 &,- 65500 & ,32827 & ,329 & $-1,5802$ & ,2702 \\
\hline & \multirow[t]{3}{*}{2} & 1,00 &,- 27528 & ,34167 & 1,000 & $-1,2382$ & ,6877 \\
\hline & & 3,00 &,- 72478 & ,26124 & ,056 & $-1,4610$ &, 0115 \\
\hline & & 4,00 &,$- 93028^{*}$ & ,25072 &, 005 & $-1,6369$ &,- 2237 \\
\hline & \multirow[t]{3}{*}{3} & 1,00 & ,44950 & ,33637 & 1,000 &,- 4985 & 1,3975 \\
\hline & & 2,00 & ,72478 & ,26124 &, 056 &,- 0115 & 1,4610 \\
\hline & & 4,00 &,- 20550 & ,24345 & 1,000 &,- 8916 & ,4806 \\
\hline & \multirow[t]{3}{*}{4} & 1,00 & 65500 & , 32827 & ,329 &,- 2702 & 1,5802 \\
\hline & & 2,00 & ,93028* & ,25072 &, 005 & ,2237 & 1,6369 \\
\hline & & 3,00 & 20550 & ,24345 & 1,000 &,- 4806 & ,8916 \\
\hline
\end{tabular}

O teste de Bonferroni indicou que há diferença significativa somente entre as médias dos itens do empirismo básico e do racionalismo tradicional $(p=0,005)$. Contudo, a diferença estatística encontrada entre as médias dos itens do empirismo básico e empirismo complexo foi de $p=0,056$, que no nível de significância de 95\% não pode ser considerado como sendo significativa, mas que indica que pode haver diferenciação dessas duas categorias, caso flexibilizemos esse nível. Essa indicação demanda um estudo com amostra maior.

Consideramos que esse seja um resultado importante principalmente em decorrência da amostra deste estudo, visto que se trata de um estudo exploratório com uma amostra pequena. Esse resultado é um indicativo de que a articulação de conhecimentos necessária para responder um item no empirismo complexo acarreta uma diferenciação de suas dificuldades em comparação com itens do empirismo básico. Ou seja, apesar de o entendimento solicitado no item ser o mesmo, o fato dele demandar um raciocínio lógico 
mais complexo ou um maior domínio matemático, o diferencia em termos do grau de dificuldade de sua versão básica.

Essa constatação evidencia a dependência que a disciplina de química tem de outras áreas do conhecimento, como a matemática. Isso é muito importante para informar ações didáticas, tanto de planejamento de ensino quanto de avaliações. O erro de um item do empirismo complexo, por exemplo, não informa de modo preciso se o estudante dispõe do entendimento químico solicitado, uma vez que pode ser devido à falta de capacidade de articulação desse entendimento com outros.

Assim, julgamos que a diferença entre os itens de natureza empírica básica e complexa deve ser investigada com mais cautela em trabalhos posteriores, com amostras maiores, a fim de fornecer resultados mais robustos.

\section{II- Configuração dos elementos do perfil epistemológico de densidade dos estudantes.}

Para avaliar como se configuram os elementos do perfil na amostra, ou seja, em que termos a amostra se comporta em relação as zonas do perfil que os testes dimensionam, analisamos a frequência de acertos dos itens que são delimitados por cada uma dessas zonas. Os itens foram agrupados de acordo com suas naturezas - realismo ingênuo $(n=1)$, empirismo básico $(n=2)$, empirismo complexo $(n=3)$ racionalismo tradicional $(n=4)$, realizamos uma frequência normalizada de acertos para cada grupo de itens.

Como havia dois questionários com itens distintos, essa etapa foi realizada separadamente para cada um dos grupos. Foi necessário realizar a análise em separado, distinguindo as amostras, uma vez que os itens de cada um dos testes eram diferentes, apesar de ambos remeterem aos entendimentos elencados no quadro 1 . 0 gráfico 2, mostra a frequência de respostas dos respondentes do teste 1 e do teste 2 .

Gráfico 2 -Percentual de frequência de respostas aos itens nos testes 1 e 2

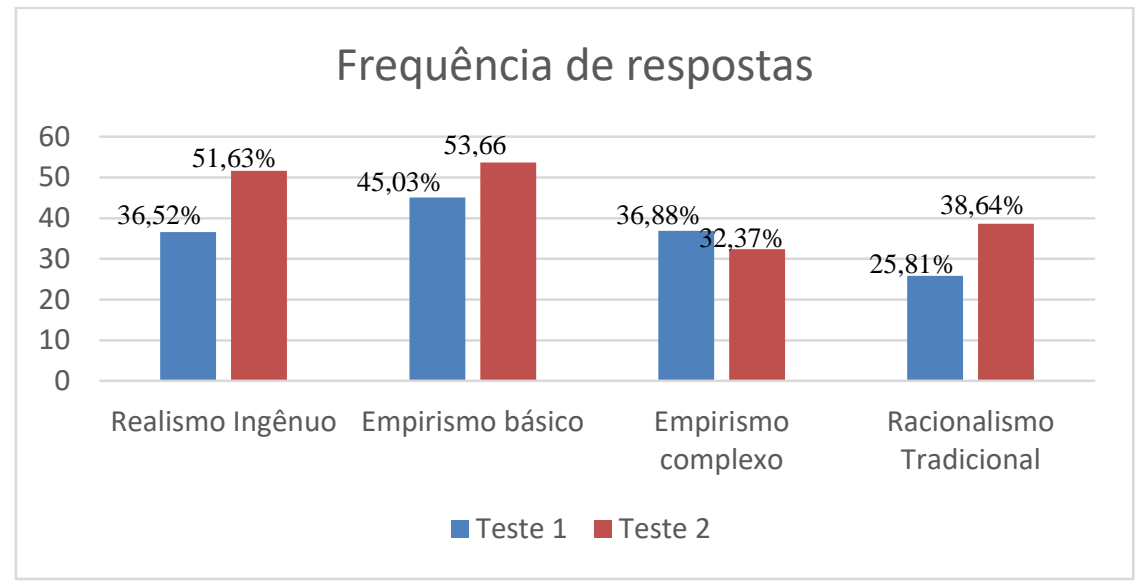

Fonte: Dados da pesquisa

O gráfico 2 apresenta barras que discriminam as porcentagens das frequências normalizadas de acertos dos itens de cada natureza em cada um dos testes. As barras azuis se referem ao teste 1 e as vermelhas ao teste 2 . Dessa maneira, temos, para cada categoria, uma frequência de acerto que nos dá margem para interpretar como se configuram os elementos do perfil das duas amostras em relação a cada zona dimensionada pelo teste. 
A depender do teste houve uma mudança no número de acertos em relação às categorias do empirismo complexo e racionalismo. Todavia, essa mudança não é preocupante visto que a análise de identificação das zonas o perfil evidenciou que não há diferença significativa de dificuldade entre os itens dessas categorias. $\bigcirc$ teste 2 apresentou maior frequência de acerto em todas as categorias, com exceção do empirismo complexo. Isso significa que provavelmente esse teste teve um índice de dificuldade menor, ou a amostra que o respondeu tinha uma habilidade maior. Essa hipótese só pode ser averiguada a partir de outras análises das médias de proficiências dos sujeitos.

Pela análise do gráfico é possível perceber que a maior frequência de acertos se refere aos itens do empirismo básico e do realismo ingênuo para ambos os testes. Em relação a identificação dos elementos do perfil da amostra, esse resultado nos diz que a maioria dos estudantes apresenta mais elementos do empirismo básico em seu perfil epistemológico. Como os itens do realismo ingênuo correspondem a itens de iniciação do perfil, o acerto indica que o estudante superou a visão do conceito no senso comum visto que ele não a usa mais no contexto escolar, sendo essa a primeira etapa na construção dos perfis epistemológicos dos estudantes.

A noção de perfil epistemológico pressupõe uma pluralidade hierárquica de modos distintos de compreender e lidar com a realidade. A primeira delas é dada pelo senso comum - realismo ingênuo, e as subsequentes - empirismo e racionalismos, são construídas como resultado do processo de escolarização. Assim, uma pessoa não escolarizada não teria um perfil epistemológico (uma pluralidade), pois disporia apenas da zona do realismo ingênuo. A superação dessa zona para o contexto escolar é uma evidência de que o estudante dispõe de mais de modo de compreender e lidar com a realidade, ou seja, mais de uma zona - o primeiro passo para a construção de seu perfil epistemológico para o referido conceito.

Ainda com relação aos itens do realismo ingênuo, era esperado que eles fossem os mais acertados dos testes, dada a hierarquia do perfil. Na análise desses itens, o acerto significa não estar na zona do realismo ingênuo, ou seja, dispor de mais de um modo, além do cotidiano, de operar com o conceito. Além disso, esses itens possibilitam outra interpretação, referente ao erro, que significa que o sujeito opera na zona do realismo ingênuo. Nesse sentido é frutífero avaliar o percentual de erro desses itens, que para o teste 1 foi de $63,48 \%$ e para o teste 2 de $48,37 \%$. Isso significa que uma parte considerável dos respondentes dos testes ainda não superou a visão de senso comum para o conceito de densidade, visto que operam ainda com elementos do realismo ingênuo no contexto escolar.

O fato de a concentração de acertos não ter sido homogeneamente distribuída entre as três zonas evidencia que, apesar dos testes terem sido construídos para o nível médio, esses estudantes podem não ter tido acesso a conhecimentos que os permitissem construir conhecimentos referentes as zonas do perfil, de acordo com a perspectiva curricular (DE MELO; AMANTES; VIEIRA, 2020). Como nossa amostra é heterogênea, formada por estudantes de nível médio e superior, é interessante analisarmos se há diferenciação da presença de elementos do perfil dessas pessoas a depender de seus níveis de escolaridade.

Essa análise do perfil, em geral, pode ser diferente a depender do nível de escolaridade, por isso é frutífero avaliar se ela se mantém para estudantes de nível médio e superior, porque a expectativa é que quanto maior o grau de escolaridade, mais elementos da zona do racionalismo surjam. Assim esperamos que os estudantes de nível superior 
tenham superado completamente a zona do realismo ingênuo e que apresentem mais elementos das zonas escolarizadas.

Para essa análise utilizamos novamente o percentual da frequência normalizada de acertos aos itens. Segmentamos os respondentes dos testes em dois subgrupos, um composto por estudantes de nível médio e outro de nível superior. As análises foram realizadas em duas etapas, uma para os respondentes do teste 1 e outra para o teste 2 . Os gráficos 3 e 4 apresentam o percentual das frequências de respostas.

Gráfico 3 -Percentual de frequência de respostas por nível de escolaridade aos itens no teste 1

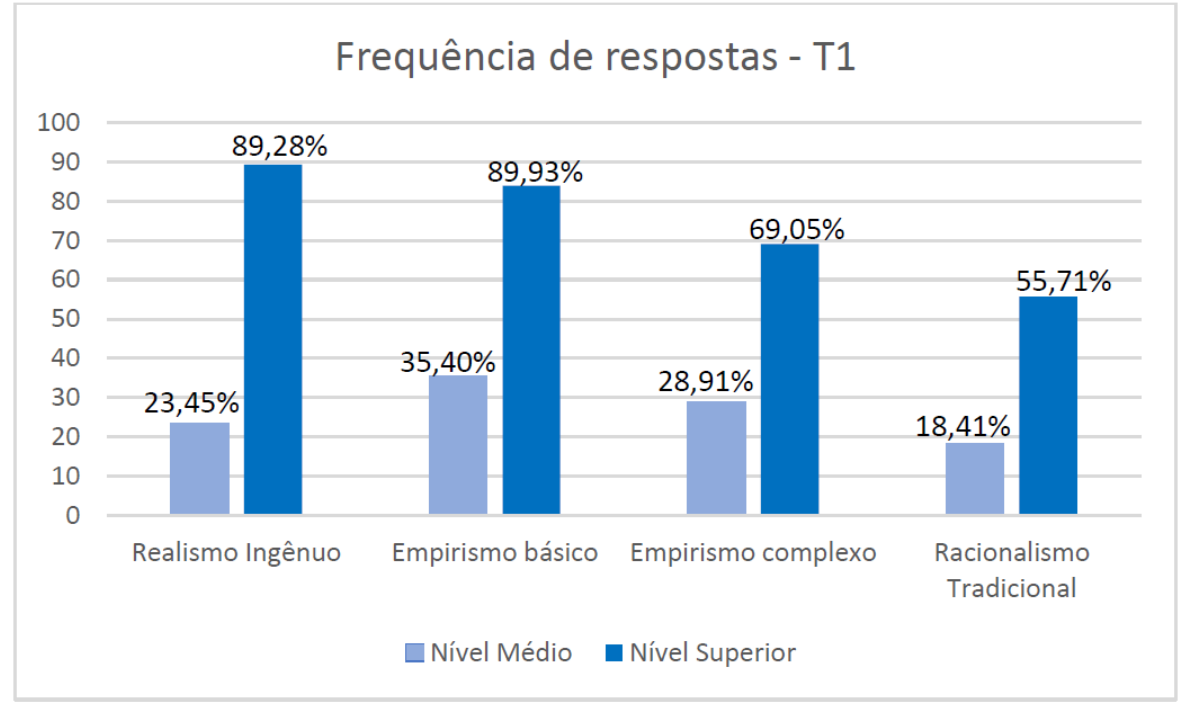

Fonte: Dados da pesquisa

Gráfico 4 -Percentual de frequência de respostas por nível de escolaridade aos itens no teste 2

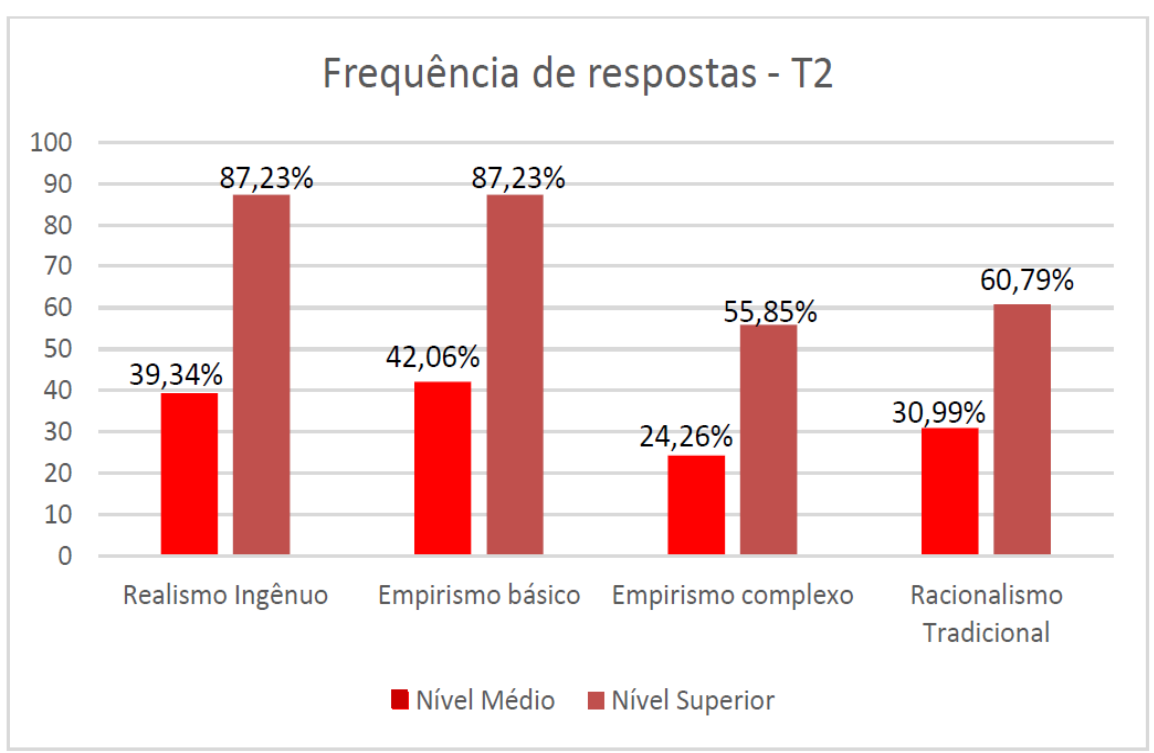

Fonte: Dados da pesquisa

Para avaliar a diferença da presença de elementos das zonas dos perfis a depender do nível de escolaridade, plotamos a frequência normalizada das respostas ao teste 1 , no gráfico 3 e ao teste 2, no gráfico 4. No gráfico 3, as barras azuis claras referem-se à 
frequência de acertos de alunos do ensino médio e as em tom escuro, aos acertos dos estudantes de nível superior. No gráfico 4, as barras em vermelho claro dizem respeito as marcações de alunos de nível médio, as em tom escuro, as de nível superior.

Podemos perceber que, para ambos os testes, há uma diferença considerável de frequência de acertos para todas as categorias de itens, a depender do nível de escolaridade dos respondentes. Isso significa que realmente os estudantes de nível superior apresentam um entendimento maior sobre o conceito de densidade, independente da zona do perfil. Do ponto de vista curricular, não era esperada tamanha discrepância entre a frequência de acertos a depender do nível do respondente, uma vez que os testes foram construídos tendo como parâmetro conteúdos de nível médio.

Em relação aos elementos das zonas do perfil reportados, tanto no teste 1, quanto no teste 2 , independentemente do nível dos respondentes, observamos uma maior frequência de acerto nas duas primeiras categorias: itens que marcam a iniciação do perfil (realismo ingênuo) e empirismo básico. Esse padrão é esperado, uma vez que esses itens, de acordo com a noção de perfil epistemológico, referem-se a entendimentos de posição inferior na escala hierárquica.

Com relação ao acerto aos itens do realismo ingênuo que marcam a iniciação do perfil, em ambos os testes eles tiveram uma baixa frequência de acertos pelos estudantes de nível médio (teste $1=23,5 \%$ e teste $2=39,34 \%$ ). Isso significa que parte considerável dos respondentes dos testes ainda não superou a visão de senso comum para o conceito de densidade. Ou seja, apesar de estarem concluindo o nível médio de escolaridade, para esse conceito em particular, a escolarização pouco teve impacto, haja vista que eles parecem não conseguir diferenciar contextos de uso.

No teste 1 , os itens com menor frequência de acerto foram os do racionalismo tradicional, o que corrobora a noção do perfil. Para o teste 2, os itens menos acertados foram os de natureza empírica complexa. Entretanto, como não há diferença estatística entre essas duas categorias, isso indica que não podemos afirmar ter evidências sobre a diferenciação entre itens de natureza empírica complexa e do racionalismo tradicional. Portanto, esse resultado, do ponto de vista empírico, não pode ser levado em consideração para interpretar a diferença de compreensão dos estudantes nessas duas dimensões, embora a hipótese teórica seja de que isso aconteça

A não corroboração da hierarquia do perfil epistemológico para a amostra de nível médio é um indicativo de que em termos conceituais não há consolidação do conhecimento. Aparentemente os estudantes dominam mais as operações matemáticas simples de uso de fórmulas (itens de natureza do empirismo básico), do que explicações conceituais. Todavia, como não investigamos a fundo essa questão, esse é um ponto a ser analisado mais detalhadamente em pesquisas futuras com amostras maiores.

\section{Considerações finais}

Neste trabalho realizamos a identificação das zonas do perfil dimensionadas pelos testes, a partir das médias de dificuldades dos itens e o mapeamento da presença de elementos do perfil epistemológico de densidade de estudantes de dois níveis distintos de escolaridade - nível médio e superior, por meio do percentual das frequências normalizada das respostas. 
Foi constatada a capacidade dos testes de dimensionar as zonas do perfil, e uma diferença significativa, se flexibilizarmos o nível de significância, entre as dificuldades de itens do empirismo básico e complexo. Consideramos que essa diferença seja um indicativo de que se deva dar mais atenção às relações de dependência que a disciplina de química tem com outras, como a matemática, por exemplo. Essa dependência deve ser considerada, tanto no planejamento de ações didáticas, quanto de ensino e avaliações. No que se refere ao ensino, o professor deve estar atento para a necessidade de articulação de outros entendimentos para além dos estritamente químicos para a aprendizagem efetiva do conteúdo; já nas atividades avaliativas, é necessário discutir os instrumentos que são utilizados para acessar o entendimento dos estudantes e quanto de conhecimento químico eles acessam.

No que se refere ao perfil da amostra, concluímos que a maioria dos estudantes de nível médio estava em vias de terminar essa etapa de escolarização sem consolidar seus conhecimentos referentes ao conceito de densidade de modo a os permitir distinguir diferentes contextos de uso: científico e cotidiano. Ademais, o baixo índice de acertos a itens da zona do racionalismo tradicional é um indicativo de que esses estudantes não se apropriaram de elementos teóricos para lidar com o conceito de densidade ao longo de sua formação.

Esses resultados levantam questões sobre as oportunidades de acesso aos conhecimentos historicamente acumulados que estão sendo oferecidas aos estudantes de nível médio de escolas públicas estaduais da Bahia. Haja vista que, mesmo que incipientes, nossos resultados alertam para uma formação em nível médio que não promove no sujeito a superação do senso comum, tampouco o instrumentaliza com elementos teóricos para compreender situações empíricas.

Nesse sentido, consideramos que o estudo ora apresentado, corrobora com os apontamentos de pesquisas da área que versam sobre a dificuldade de aprendizagem do referido conceito. Porém, com o detalhamento da qualidade de cada uma das facetas do conceito possibilitado pela noção perfil epistemológico. Essa lente teórica nos permitiu destrinchar as facetas do conceito, como pode ser observado no quadro 1, o que pode ser muito útil para direcionar o planejamento didático, de modo a possibilitar que os estudantes construam todas as zonas do perfil epistemológico de densidade para o referido nível de escolaridade.

Consideramos necessário o investimento em mais pesquisas, que envolvam estudantes de diferentes escolas, a fim de evidenciar o impacto da formação a qual eles estão sendo submetidos. Nesse sentido, um instrumento baseado na noção de perfil epistemológico tem muito a contribuir para evidenciar o quanto o processo de escolarização fornece, ou não, condições para que os estudantes superem as visões de senso comum e consigam operar com teorias científicas para interpretar fenômenos empíricos. 


\section{Referências}

AGUIAR, M. S. F. Aprendizagem de conceitos físicos a partir de um jogo didático. 2018, 274p. Tese (Doutorado em Ensino, Filosofia e História das Ciências) - Instituto de Física, Universidade Federal da Bahia/ Universidade Estadual de Feira de Santana, Salvador, 2018.

BACHELARD, G. A Filosofia do Não; In: Os Pensadores. São Paulo: Abril Cultural, p. 01-87, 1979.

BACHELARD, G. A Formação do espírito científico: contribuição para uma psicanálise do conhecimento. $3^{a}$ reimpressão. Rio de Janeiro: Contraponto, 1996, 316p.

DE MELO, V. F.; AMANTES, A.; VIEIRA, R. D. Construção de uma taxonomia sobre o entendimento do conceito científico de densidade baseada na noção de Perfil Epistemológico. Ensino, Saúde e Ambiente, Niterói, v.13, n.1, p. 161-182, abr. 2020.

FARIA, A. G. V. Densidade x forças intermoleculares-uma proposta de Superação de um obstáculo epistemológico. 2010, 69p. Dissertação (Mestrado em Ensino) -Universidade Federal de Mato Grosso do Sul, Campo Grande, 2010.

FASSOULOPOULOS, G.; KARIOTOGLOU, P.; KOUMARAS, P. Consistent and inconsistent pupils' reasoning about intensive quantities: The case of density and pressure. Research in Science Education, v. 33, n. 1, p. 71-87, 2003. DOI 10.1023/A:1023658419034. Disponível em: https://doi.org/10.1023/A:1023658419034. Acesso em 8 maio 2020.

HASHWEH, M. Z. The complexity of teaching density in middle school. Research in Science \& Technological Education, v. 34, n. 1, p. 1-24, 2015. DOl 10.1080/02635143.2015.1042854. Disponível em https://doi.org/10.1080/02635143.2015.1042854. Acesso em 14 maio 2020.

HAWKES, S. J. The concept of density. Journal of Chemical Education, v. 81, n. 1, p.14-15, jan. 2004.

IBM_CORP. IBM SPSS Statistics for Windows, Version 20.0. IBM Corp. New York. 2011.

LINACRE, J. M. WINSTEPS 3.70. Rasch measurement computer program, Chicago.

Winsteps.com, 2010. Disponivel em: <Winsteps.com>.

MELO, V. F. Investigando o entendimento sobre densidade à luz da noção de Perfil Epistemológico e do Autoconceito em Química. 2020, 291p. - Tese (Doutorado em Ensino, Filosofia e História das Ciências) - Faculdade de Educação, Universidade Federal da Bahia/Universidade Estadual de Feira de Santana, Salvador, 2020.

MERÇON, F. O que é uma gordura trans. Revista Química nova na escola, São Paulo, v. 32, n. 2, maio 2010.

MORTIMER, E., F; MACHADO, A., H; ROMANELLI, L., I. A proposta curricular de química do Estado de Minas Gerais: fundamentos e pressupostos. Química Nova, São Paulo, v. 23, n. 2, p. 273-283, 2000.

PEREIRA, M. M. Do Empírico Ao Teórico: Um Plano de Aula para o Ensino do Princípio de Arquimedes no Ensino Médio. - Instituto de Física, Universidade Federal do Rio de Janeiro (UFRJ), 2009.

ROSSI, A.V. et al. Reflexões sobre o que se ensina e o que se aprende sobre densidade a partir da escolarização. Química Nova na Escola, São Paulo, n. 30, p. 55-60, nov. 2008. 
ROWELL, J; DAWSON, C. Teaching about floating and sinking: An attempt to link cognitive psychology with classroom practice. Science Education, v.61, n. 2, p. 245-253, 1977.

DOl10.1002/sce.3730610215. Disponível em: https://doi.org/10.1002/sce.3730610215. Acesso em 02 junho 2021.

SANTOS, A. I.; CERVI, G. M. Conduzindo as condutas: o novo Ensino Médio brasileiro, uma estratégia biopolítica de governo. Anais do Colóquio Luso-Brasileiro de Educação-

COLBEDUCA, v. 3, 2018.

SMITH, C; CAREY, S; WISER, M. On differentiation: A case study of the development of the concepts of size, weight, and density. Cognition, v. 21, n. 3, p. 177-237, 1985. DOl10.1016/00100277(85)90025-3. Disponível em: https://doi.org/10.1016/0010-0277(85)90025-3. Acesso em 02 junho 2021.

SOUZA, P. V. T. et al. Densidade: Uma Proposta de Aula Investigativa. Química Nova na Escola, São Paulo, v. 37, n. 2, p. 120-124, maio 2015.

$X U, L ; C L A R K E, D$. Student difficulties in learning density: A distributed cognition perspective. Research in science education, v. 42, n. 4, p. 769-789, Ago. 2012. 